\title{
Promoting integrity of shift report by applying ISBAR principles among nursing students in clinical placement
}

\author{
Weng Ian Pang ${ }^{1 \mathrm{a}}$, \\ ${ }^{1}$ PHD student, Faculty of Health Sciences, Macau University of Science and Technology. Lecturer, \\ School of Health Sciences, Macao Polytechnic Institute, Rua de Luis Gonzaga Gomes, Macao
}

\begin{abstract}
Shift report is an essential method for nursing staff to carry out health care communication. The most important purpose of the shift report is to ensure the safety of patients and to provide continuous care. Nursing students are inadequate of clinical experience and rational organization during patient care. They may not be able to handle the critically ill patients and pass the messages to the following nursing staff. ISBAR (Identify, Situation, Background, Assessment and Recommendation) tool is increasingly being utilized as a format for structured shift report communication. In this study, a scale of ISBAR principles is designed to provide students with self-assessment and teachers with evaluation, in a way to improve nursing students' self-awareness of shift report. Hopefully, with the use of the scale of ISBAR, nursing students are able to complete shift report in systemic integrity and orderliness during clinical placement.

Keywords: Shift report; nursing students; ISBAR principles
\end{abstract}

\section{Introduction}

Good communication is recognized as essential to quality and patient safety, and good communication skills are integral part of health professional expertise [1]. It has long been recognized that shift report is an essential method for nursing staff to carry out health care communication. Clinical handover refers to the transfer of professional responsibility and accountability for some or all aspects of care for a patient, or group of patients, to another person or professional group on a temporary or permanent basis [2]. Handovers can only be achieved through linguistic exchange. So, when this communication is suboptimal, patient safety is compromised [3,4]. Incident and complaint data provide strong evidence for the critical role of lack of appropriate communication in adverse events [5]. Australian and international agencies recognize the imperative to act to improve clinical communication [6]. Its effectiveness has been demonstrated in clinical using a standardized format, which can assist the transfer of information, improve the quality of clinical communication and

\footnotetext{
${ }^{\text {a }}$ Corresponding author: author@e-mail.org
} 
prevent subsequent medical errors. [4, 7-9]. Therefore, the most important purpose of a standardized format shift report is to ensure the safety of the patient and to provide continuous care.

The Joint Commission and the Institute for Healthcare Improvement recommend the SBAR (situation, background, assessment, recommendations) communication technique to improve communication and reduce medical errors [10]. JCAHO [4] recommend that ISBAR (Identification, Situation, Background, Assessment, and Recommendation) is a tool, which may improve communication within multidisciplinary teams. ISBAR tool be utilized as the model that all healthcare staff use to structure clinical communication, and ensuring accurate handover of information between shifts $[4,7]$. The ISBAR framework can organize this information in a clear and concise format (Table 1), which includes a summary of the patient's medical history, illness history, pathophysiology, laboratory data, current situation and nursing care information $[7,11]$.

Nursing students lack experience in interprofessional communication skills, being overwhelmed with organizing and are unable to accurately presenting their patient's information in clinical. They may not be able to handle the critical ill patients and pass the messages to the following nursing staff. Also, students are fear of making mistakes, making learning difficult and lose self-confidence. A study of Davis [12] found that the time for preconference was shortened during the clinical placement, while discussion was focused on pertinent information. Students also reported less anxiety when presenting with the modified SBAR format. However, nursing students' clinical learning experiences are important components of their professional development [13].

Table 1. ISBAR https://www.inmo.ie/tempDocs/ISBAR_PAGE46-47\%20feb13.pdf

\begin{tabular}{ll}
\hline \multicolumn{1}{c}{ Items } & \multicolumn{1}{c}{ ISBAR } \\
\hline $\begin{array}{l}\text { Identify } \\
\text { Situation }\end{array}$ & Identify yourself, who you are talking to and who you are talking about \\
Background & What is the current situation, concerns, observations, etc.? \\
& What is the relevant background? This helps to set the scene to interpret the \\
& situation above accurately \\
Assessment & What do you think the problem is? This requires the interpretation of the \\
& $\begin{array}{l}\text { situation and background information to make an educated conclusion } \\
\text { about what is going on } \\
\text { Recommendation }\end{array}$ \\
& $\begin{array}{l}\text { What do you need them to do? What do you recommend should be done to } \\
\text { correct the current situation? }\end{array}$ \\
\hline
\end{tabular}

Faculty are challenged continuously to improve communication skills among nursing students preparing them for safe clinical practice. ISBAR principle can improve the relevance of teaching and management strategies. Regarding the improvement in both clinical practice preparation and communication competency of nursing students, Skaalvik, Normann, \& Henriksen [13] found that oral shift reporting can stimulate learning if it includes consultation and discussion between nursing students and the nursing staff. Therefore, to enhance students' organizational skills and ability to assess patient, students are educated the learning strategy as a measurement for integrity of shift report after they have finished their shift handover. Through using assessment form with a standardized rubric as the learning strategy for teaching and evaluating communication in clinical handover, it will then provide quality and safety in students' education.

Communication is a complex phenomenon and includes skill, cognition, emotion, and value [9]. Raya [14] stated nursing practice requires not only scientific knowledge, but also interpersonal, intellectual and technical abilities and skills; this means a composition of knowledge, clinical work and interpersonal communication. Although there is a standardized ISBAR format to help student to transfer information, nursing students also 
need shared responsibility for timely, relevant, clear, and concise exchange of patient information with a cadre of disciplines often in hectic, chaotic environments in order to assure good communication among them [9]. Hence, there are four parts in the assessment criteria including SBAR, professional attitude, nursing knowledge and communication skills.

The author of the present study took a qualitative research approach to explore the promoting integrity of shift report by applying ISBAR principles among nursing students in clinical placement. The aims of this study were to provide an evaluation method for shift report among nursing students during clinical placement, to develop the standards for guiding their efforts to target, to develop students with self-improvement, and to facilitate clinical preceptor to focus on students-to-nurse communication evaluation.

\section{Method}

A pilot study was initiated with designed evaluation methods among nursing students to assess the outcomes of the application of ISBAR. Evaluation of professional attitude, SBAR skill, knowledge and communication skills were the focus of the study assessment criteria.

\subsection{Participants}

The study was recruiting nurse managers and advanced nurses from a government hospital who were baccalaureate, licensed clinical nurse specialist with a minimum of five years' teaching experience in nursing who also took part in grading the students. A total of five participants voluntarily and anonymously took part in this study, with four nursing preceptors and one head nurse (Table 2).

Table 2. Participants in the interviews

\begin{tabular}{lllll}
\hline Participant & Gender & Ward & Education & Experience (Year) \\
\hline 1 & Female & Medical & BSN, CNS & $>30$ \\
2 & Female & Medical- & BSN, CNS & $>30$ \\
3 & Female & Surgical & BSN, MSN with CNS & $>15$ \\
4 & Female & Critical & BSN, MSN with CNS & $>15$ \\
5 & Male & Critical & BSN, CNS & $>10$ \\
\hline
\end{tabular}

BSN: Bachelor of Science in Nursing; CNS, Clinical Nurse Specialist

MSN with CNS: Master of Science in Nursing (MSN) with Clinical Nurse Specialist (CNS)

\subsection{Procedure}

Data collection took place in the government hospital. Interview with the five advanced nurses that included one head nurse and four nursing preceptors began in mid-March and ended in mid-April 2016. At the beginning of each interview, the participant confirmed that the interview could be recorded. The interviews were conducted in Cantonese.

Data collection and analysis of clinical preceptors and head nurses focused on the shift reports requirements for the nursing students. The interview questions (Table 3) were structured following literature reviews, mainly indicating nursing students' professional 
attitude, nursing knowledge, communication skills and narrative thinking as the development and application of the evaluation criteria.

Table 3. Interview questions

Interview questions

1. What are your comments regarding the shift handover of nursing students?

2. Are you satisfied with the handover of nursing students? Why?

3. From a professional attitude point of view, which items of handover are important? Why?

4. What are your comments/suggestions regarding the organization ability of nursing student to shift handover? Please explain.

5. Do you think nursing students need to have sufficient nursing knowledge to shift handover? Why?

6. What do you think about using assessment criteria of ISBAR for nursing students? Please explain.

7. Do you think the nursing student's communication skills are related to the handover? Why?

8. Do you have any case about the shift handover of nursing student? Please explain.

\section{Results and discussion}

The transcribed data of all participants were read and organized into categories or selection of themes. When similar or identical items were found in most or all of the individual transcriptions, they were grouped into concepts, which were then examined to determine themes.

The interviews of all five nurse managers and advanced nurses were identified and analyzed in four major concepts (Figure 1): (1) Professional attitude of students. (2) SBAR (Situation, Background, Assessment, Recommendation). (3) Knowledge of nursing care and medications. (4) Effective communication skills. The details of each concept are further explained below under the four themes.

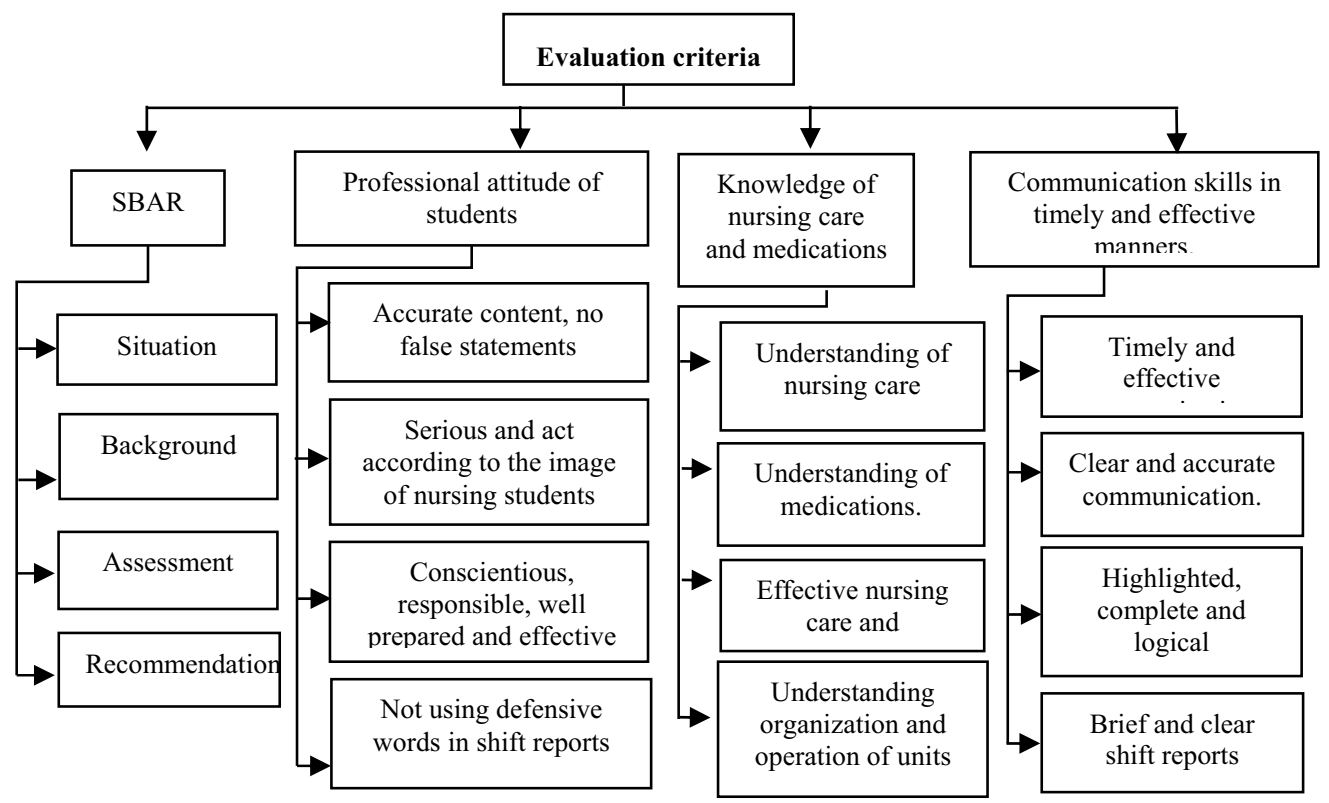

Figure 1. Evaluation criteria 


\title{
3.1 SBAR
}

ISBAR is the most important concept in the theme that included Identification, Situation, Background, Assessment, and Recommendation. The ISBAR approach holds great promise to enhance communication as a simple, portable and memorable tool which can be used by anyone to optimize communication, especially for nursing student [8].

In the first concept, the interviewers explored this area in detail. The nurse manager and one of the advanced nurses stated that there are usually a lot of students who could not understand and failed to grasp the patient's situation, especially being neglectful in considering the patient's background and lack in providing recommendation for patients. Some of the participants' comments on students using the ISBAR principle to clinical handover are:

\begin{abstract}
'What are your comments regarding the shift handover of nursing students? The year 3 students cannot understand how to complete description of the patient's situation. The students do not understand what patient's data is needed to be expressed, they also often ignore the patient's history and recommendations. If there is a systematic form for guidance on how to handover, that will help improve students' ability to express and organize.'
\end{abstract}

'ISBAR is a good way for students to shift and can help improve students' self-confidence, as well as to help students better understand the patient's condition.'

In terms of judgment for the score of this assessment criteria, as ISBAR is the most important concept among the themes, it comprises $40 \%$ of marking in this form and a 10 point system was applied to assess students" understanding. The "I" in ISBAR which is "Identification" refers to "Identify yourself, who you are talking to and who you are talking about". However, all participants commented that it was not suitable to use the 10-point system on "Identification", and they agreed to transfer the "Identification" score to professional attitude of students in assessment criteria. Therefore, the format (Table 4) for the preparatory work were changed to a modified version that became Situation, Background, Assessment, and Recommendation (SBAR).

"The "Identification" in ISBAR, which is a basic requirement in handover, should not be included in the 10-point system; the scores arrangements should be considered more appropriate in the professional attitude of students.'

Table 4. SBAR

\begin{tabular}{|c|c|c|c|c|c|c|c|c|c|c|}
\hline \multirow{2}{*}{$\begin{array}{c}\text { Performance } \\
\begin{array}{l}\text { Situation: Able to describe the current } \\
\text { situation, concerns, observations, etc. }\end{array}\end{array}$} & \multicolumn{2}{|c|}{$\begin{array}{l}\text { Excell } \\
\text { ent }\end{array}$} & \multicolumn{2}{|c|}{ Good } & \multicolumn{2}{|c|}{ Fair } & \multicolumn{2}{|c|}{ Acceptable } & \multicolumn{2}{|c|}{ Poor } \\
\hline & 10 & 9 & 8 & 7 & 6 & 5 & 4 & 3 & 2 & 1 \\
\hline $\begin{array}{l}\text { Background: Able to give a summary of } \\
\text { information relevant to the current } \\
\text { problem: medical history, medications, } \\
\text { laboratory results, diagnostic tests, etc. }\end{array}$ & 10 & 9 & 8 & 7 & 6 & 5 & 4 & 3 & 2 & 1 \\
\hline $\begin{array}{l}\text { Assessment: Able to provide background } \\
\text { information, found on examination of the } \\
\text { patient, progress and results. }\end{array}$ & 10 & 9 & 8 & 7 & 6 & 5 & 4 & 3 & 2 & 1 \\
\hline $\begin{array}{l}\text { Recommendation: Able to provide follow- } \\
\text { up action, direction, prevention, etc. }\end{array}$ & 10 & 9 & 8 & 7 & 6 & 5 & 4 & 3 & 2 & 1 \\
\hline
\end{tabular}




\subsection{Professional attitude of students}

From the respondents' descriptions, the professional attitude of students in clinical handover is mostly concerned by the nurses. All advanced nurses in the interviews reported that the demand from clinical handover involved professional attitude as they requested students to be serious, rigorous and responsible for their action.

'Nursing students should be serious when passing the messages to the following nursing staff during shift reports.'

Question 4 dealt with the comments/suggestions regarding the organization ability of nursing student in shift handover (Table 3). The nurse manager and one of the advanced nurses stated that the patient's report content must be accurate, so the item "no false statement" is very important when composing the shift report. One of the advanced nurses indicated that students should not use offensive words, complain nor attack someone in the shift reports.

'A student used offensive words in shift report; the student blamed a male patient who did not finish lunch by himself, and then she also criticized her patient for being useless and needed help to finish his lunch.'

In terms of judgment for the score of this assessment criteria, as professional attitude is an important concept in the themes, this part comprises $20 \%$ of total marking in this form. This time we used a 5-point system to assess the students' understanding. All participants mentioned that nursing profession must acquire professional attitude. Each nurse needs to understand the responsibilities and concerns that are integrated to the nursing profession [15]. The professionalism in the nursing field is defined as non-biased care for patients, integrity, respect for patients, attitude, appearance, willingness to help others, team work, honesty, responsibility and discipline [15]. These are the core values of nursing professional that are expected and appreciated. Nurses should possess responsibility, honesty, integrity, belief in human dignity and patient equality [15].

Ascano-Martin [16] stated that omission of vital patient information including the patient's age, sex, race and medical history is common when transferring information from one professional to another. It also reflects the lack of professional attitude during clinical handover. Therefore, the modified format (Table 5) included no false statement, Seriousness, responsibility, preparedness of shift reports, effectiveness of introduction and free of offensive words, etc.

Table 5. Professional attitude of students

\begin{tabular}{lccccc}
\hline \multicolumn{1}{c}{ Performance } & $\begin{array}{c}\text { Excell } \\
\text { ent }\end{array}$ & Good & Fair & Acceptable & Poor \\
\hline Accurate content, no false statement & 5 & 4 & 3 & 2 & 1 \\
$\begin{array}{c}\text { Serious and act according to the image of } \\
\text { nursing students }\end{array}$ & 5 & 4 & 3 & 2 & 1 \\
$\begin{array}{c}\text { Conscientious, responsible, well-prepared in } \\
\text { shift reports and effective introduction }\end{array}$ & 5 & 4 & 3 & 2 & 1 \\
$\begin{array}{c}\text { Not using offensive words in shift reports such } \\
\text { as criticism, blaming, complaining and }\end{array}$ & 5 & 4 & 3 & 2 & 1 \\
attacking someone, etc. & & & & & \\
\hline
\end{tabular}




\title{
3.3 Knowledge of nursing care and medications
}

According to the participants' descriptions and their experience in teaching students, students who lack knowledge are more likely to make mistake when transferring critical information during clinical handover. Question 5 dealt with the need of nursing students to have sufficient nursing knowledge for shift handover (Table 3). For the interviews of all 5 nurse managers and advanced nurses, information indicated that the students should enhance their nursing knowledge in order to identify the clinical problem and to effectively deliver the messages for following nurses, particularly in pathophysiology, pharmacology, critical care, medical and surgical care. Clarke [17] suggested that understanding handover improvement complexities can enhance problem recognition and increase the likelihood of achieving successful outcomes in subsequent stages of change. The nurse manager has more detailed sharing on this issue:

\begin{abstract}
'Students and recent graduates still need to further develop their vital knowledge, especially in medication. Usually, students do not understand why the patients are taking the drug, and not understanding the precautions for the medication, so, they cannot verbally explain the situation of patient about the drug when they undergo clinical handover.'
\end{abstract}

In terms of judgment for the score of this assessment criteria, as the knowledge of nursing care and medications is an important concept in these themes, this part comprises $20 \%$ of total marking in this form. A 5-point system was used here to assess the students' understanding. Smith and Kaluzny [18] stated that solution identification follows problem recognition in a process that is influenced by characteristics of both the organization and of the solution. It is therefore important to understand the organization and operation of ward to ensure that solutions will be successful in overcoming handover complexity and context variability. Therefore, the most major considerations or factors in this format (Table 6) included understanding of medication, understanding of nursing care, effective nursing care and treatments and understanding of organization and operation in wards.

Table 6. Knowledge of nursing care and medications

\begin{tabular}{lccccc}
\hline \multicolumn{1}{c}{ Performance } & $\begin{array}{c}\text { Excell } \\
\text { ent }\end{array}$ & Good & Fair & Acceptable & Poor \\
\hline Understanding of nursing care & 5 & 4 & 3 & 2 & 1 \\
Understanding of medications & 5 & 4 & 3 & 2 & 1 \\
$\begin{array}{l}\text { Effective nursing care and treatments } \\
\begin{array}{l}\text { Understanding organization and operation of } \\
\text { units }\end{array}\end{array}$ & 5 & 4 & 3 & 2 & 1 \\
\hline
\end{tabular}

\subsection{Effective communication skills}

As the clinical care environment has progressively become more complex, there are needs to reinforce the belief that the improvement in students' communication during clinical handover are best for managing complex environments. Manning [9] stated that communication skills included listening, assimilating, interpreting, gathering, and sharing information. Question 7 dealt with the nursing students' communication skills that are related to the handover (Table 3). The nurse manager mentioned that students' verbal 
handover of the content is not logical, not highlighting the patient's problem, and not clear in the shift report. According to WHO Patient Safety Solutions [19], these gaps in communication can cause serious breakdowns in the continuity of care, inappropriate treatment, and potential harm to the patient. All participants agreed with the necessity of communication skills for safe transfer of information. They also believed that the transfer of messages should be timely and effective, and that the content should be clear and accurate. One of the advanced nurses stated about some issues found in the communication skills in students:

'Students often forget the important message when they orally present the shift reports. The students did not timely inform to the nurses the need to follow the situation, which implies the lack of organizational capacity of students' communication.'

In terms of judgment for the score of this assessment criteria, as communication skills is an important concept in these themes, this part comprises $20 \%$ of total marking in this form. A 5-point system was used to assess the students' understanding. Kourkouta and Papathanasiou [1] observed the results of their study and stated that good communication also improves the quality of care provided to patients. There is a strong emphasis in identifying the communication skills of students during clinical handover that can contribute to, or protect against, preventable medical errors. Therefore, good communication of assessment criteria in shift report can ensure patient's safety and reduce error susceptibility. The most major considerations or factors in this format (Table 7) included timely, effective, complete, logical and clarified communication in shift reports.

Table 7. Effective communication skills

\begin{tabular}{lccccc}
\hline \multicolumn{1}{c}{ Performance } & Excellent & Good & Fair & Acceptable & Poor \\
\hline Timely and effective communication & 5 & 4 & 3 & 2 & 1 \\
$\begin{array}{l}\text { Clear and accurate communication } \\
\text { Highlighted, complete and logical }\end{array}$ & 5 & 4 & 3 & 2 & 1 \\
$\begin{array}{c}\text { communication } \\
\text { Brief and clear shift reports }\end{array}$ & 5 & 4 & 3 & 2 & 1 \\
\hline
\end{tabular}

\section{Conclusions}

This study demonstrated that expected outcomes improves student communication that using a scale of ISBAR principles that may improve student shift report in systemic integrity and orderliness. The concerns expressed by our interviewees about the students lack the ability to transfer the important information during clinical handover, if not addressed properly compromise student's ability to transfer in oral shift reports while adding to the serious breakdowns in the continuity of care. Therefore, the assessment criteria as a learning strategy and measurement for integrity of shift report after they have finished their shift handover. It can be provides a guidance for student in shift handover and promotes a scoring scheme for teacher to recognize shortage of student in shift reporting. 


\section{References}

1. L. Kourkouta, L.V. Papathanasiou, Communication in Nursing Practice. Mater Sociomed, 26(1), 65-67., (2014)

2. Australian Medical Association. Safe handover: safe patients. AMA Clinical Handover Guide. Sydney, (2006).http://ama.com.au/node

3. C.C. Greenberg, S.E. Regenbogen, D.M. Studdert, S.R. Lipsitz, S.O. Rogers, M.J. Zinner, A.A. Gawande, Patterns of communication breakdowns resulting in injury to surgical patients. J. Am. Coll. Surg. 204: 533-540. (2007)

4. JCAHO. Sentinel event statistics. (2006). http://www.jointcomission.org/sentinelevents/statistics/

5. K. Hill, R. Aldrich, D. Lawson, T. Easton, Enhancing Clinical Communication: Characterizing the Role of Communication in Clinical Incidents and Complaints International Society for Quality in Health Care Conference, Boston. (2007)

6. Australian Commission on Safety and Quality in Health Care. The OSSIE Guide to Clinical Handover Improvement. Sydney, ACSQHC, (2009). https://www.safetyandquality.gov.au/wp-content/uploads/2012/01/ossie.pdf

7. M. Horgan. ISBAR stickers may improve communication within multidisciplinary teams, ensuring accurate handover of information between shifts. (2013). https://www.inmo.ie/tempDocs/ISBAR_PAGE46-47\%20feb13.pdf

8. R. Aldrich, A. Duggan, K. Lane, K. Naīr, K.N. Hill, ISBAR revisited: identifying and solving barriers to effective clinical handover in inter-hospital transfer - public report on pilot study. Newcastle: Hunter New England Health (2009). https://www.safetyandquality.gov.au/wp-content/uploads/2012/01/ISBAR-PSPR.pdf

9. M.L. Manning. Improving clinical communication through structured conversation. Nurs. Econ., 24(5), 268-271. (2006).

10. Institute for Healthcare Improvement. Web and action: using SBAR to improve communication. (2006).http://www.ihi.org/ihi/fbmms/Sh()wForum^spx?ForumID:97

11. Medical Audits. Medical Audits ISBAR Audit Tool. (2015). http://www.medicalaudits.co.uk/sepsis_isbar.aspx

12. R.L. Davis, Using SBAR as a Preconference Reporting Tool for Nursing Students. Nurse Educ. 41(2). Copyright * 2016 Wolters Kluwer Health, Inc. All rights reserved

13. M.W. Skaalvik, H.K. Normann, N. Henriksen, To what extent does the oral shift report stimulate learning among nursing students? A qualitative study. 19(15-16), 2300-2308. (2010)

14. A. Raya. Nursing of man as a unique person Nosileftiki. 45(1): 19-24. (2006)

15. Health eCareers. How important is professionalism for a Nurse? (2011).https://www.healthecareers.com/article/healthcare-news/how-important-isprofessionalism-for-a-nurse

16. F. Ascano-Martin. Shift report and SBAR: strategies for clinical post conference. Nurse Educ. 33(5), 190. (2008).

17. C.M. Clarke, D.D. Persaud, Leading Clinical Handover Improvement: A Change Strategy to Implement Best Practices in the Acute Care Setting. J Patient Saf. 7(1):1118. (2011)

18. D. B. Smith, A.D. Kaluzny, The White Labyrinth: A Guide to the Health Care System. 2nd Edition. Ann Arbor, MI: Health Administration Press, (1986)

19. WHO Patient Safety Solutions. Communication during patient hand-overs (2007) http://www.who.int/patientsafety/solutions/patientsafety/PS-Solution3.pdf 